\title{
The scars of COVID19: Preparing for the collateral damages
}

\author{
Ruby Dhar ${ }^{1}$, Babban Jee ${ }^{2}$, Karthikeyan Pethusamy ${ }^{3}$, Ashikh Seethy ${ }^{4}$, Arun Kumar ${ }^{5}$, \\ Subhradip Karmakar ${ }^{6}$
}

${ }^{1} \mathrm{PhD}$ Scientist, Department of Biochemistry, AlIMS, New Delhi, India, ${ }^{2}$ Scientist-C, Department of Health Research, Ministry of Health and Family Welfare Government of India, ${ }^{3,4} \mathrm{MD}$ (AIIMS) and PhD Fellow, Department of

Biochemistry, AIIMS, New Delhi, India, ${ }^{4}$ Professor and Head, Department of Biochemistry, Jagannth Gupta Insitute of Medical Sciences, Jagannath Gupta Insitute of Medical Sciences, Budge Budge, Kolkata 700137, ${ }^{5}$ Associate Professor and Team Leader, Department of Biochemistry, AlIMS, New Delhi, India

COVID-19 is a pandemic of disproportionate magnitude. Its devastating effect seems to have a more significant impact on the emerging economies like India and the rest of SE Asia, which also has regions harbouring some of the world's highest population density living under poor socio-economic condition. What seems to have originated from one just one province in China, rapidly speard like wildfire across international territories, affecting millions and crippling the health care system. After about eight months into COVID-19, we realized that the fallout is not only humongous but also stretched across multiple avenues of the society and different aspects of our life. The scars of COVID-19 are much more than the virus itself. With a global shutdown in business and financial institutions, the economy is in free fall. Markets plummeted, stocks crashed and unemployment numbers skyrocketed. Apart from the economy, COVID-19 related shutdown has a tremendous impact on the healthcare system for those with preventable ailments, which were either compromised or delayed affecting millions who need hospitalization for non-COVID causes. COVID crisis also seems responsible for the emergence of a new culture system and mindset that was unprecedented before. With schools and other academic institutions closed, online teaching through electronic media and work from home became the new normal. In this editorial, we summarized the collateral damage on society, economy, and human health in the COVID crisis and few suggestions to chalk out a new plan and strategy to address the challenges for a future episode of similar nature. Though we could still remain vulnerable against similar contagious agents, an advanced planning strategy and preparedness will surely help us better in effective damage control and risk mitigation, not only to reduce mortality, but also from economic downfall.
Access this article online

Website:

http://nepjol.info/index.php/AJMS DOI: 10.3126/ajms.v11i6.30660

E-ISSN: 2091-0576

P-ISSN: 2467-9100

Copyright (c) 2020 Asian Journal of Medical Sciences

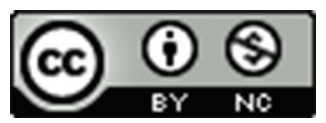

This work is licensed under a Creative Commons Attribution-NonCommercial 4.0 International License.

Key words: COVID19; Pandemic; Economy; Public health

\section{INTRODUCTION}

While the Marium Webster defines an epidemic as an "outbreak of a disease that occurs over a wide geographic area and affects an exceptionally high proportion of the population," Oxford University Press has a slightly different definition. According to it, a pandemic is defined as "an epidemic occurring worldwide, or over an extensive area, crossing international boundaries and usually affecting a large number of people." While these definitions have an emphasis on its extensive spread, it fails to clarify on the fatality, transmissibility as well as disease severity1. As if this is not enough, we have an "epidemic," "endemic," and "outbreak" in the list to add to the confusion. It is clear that as the disease evolves, it changes the definition as the way people perceive it. And then we have the disease statistics that drive these changes. Added to these are layers of additional modifiers like political and socio-economic interest(A pandemic will be treated as a national emergency usually associated with allocations of maximum government aid). COVID19 possibly is one of the best examples in the recent times 
of our mixed response and dynamic landscape of decision making. While still restricted in Wuhan, China (supposedly where it originated), COVID19 was an epidemic that slowly became an outbreak and eventually a Pandemic after a month when it spread to several countries, infecting millions of individuals.

To begin with, that makes COVID19 even an endemic to that place. Not only are we riddled with how to classify COVID19, but there are additional dilemmas that we are not yet prepared to handle effectively. While a thrust of the efforts is devoted to tackling this disease from a healthcare perspective, the real threat seems to loom at the periphery. These are the collateral damages that need to be addressed in this review with a note that the post COVID19 world might be quite different than what we are enduring now. COVID19 pandemic will have a profound influence on our everyday life for years to come. The effect on economic and human health are astronomical. Loss of employment due to the shrinking economy and spending power of government and rise in nonCOVID related casualties are just too large to ignore. It has exposed our vulnerabilities and lacunae in policymaking and implementation as much as it has been realized to the world with new genres of heroes and patriots, who don't carry guns or fly fighter jets. They are our healthcare physicians, nurses, community and utility workers, teachers, and police personals. We have witnessed their selfless duty for the nation, risking their own life. The Post-COVID era will redefine the way we percept life and rebuild ourselves in a new way fighting with a formidable invisible enemy, together with joining hands, keeping aside our ideology and political affiliations.

Ever imagined how a mere disease could completely overhaul the human perception and mindset and have a profound impact on our behavior and decision making? The last five months' online search survey revealed COVID19 and Coronavirus as the top two most queried items on Google and Bing search engines. Suddenly people are eager to learn more about them. Linguistic adaptations to new memes like "social distancing," "quarantine", "lockdown", "staggering exit" have become a commonplace. Hotspots, clustered zones, decontaminations, self-quarantine, pandemic are extensively discussed in almost any conversation. It's not just the cough or droplet contaminations that are spreading the disease; its also the media with their 24X7 bombardment visible on any LED screen with anchors, panelists, experts, health care professionals, speculators, policymakers .. everyone has to something to add to the COVID19 story. A rather obscure virus riding on bats, fish, and pangolins for decades suddenly became the diva of the tinsel town. Hanging on from the bodies of horseshoes bats in some dark, moist cave for centuries, the virus has since traveled the whole world joyriding over twenty million human bodies in just over eight months.
There is also a significant loss in human life. The USA tops the list with nearing five million casualties. COVID19 is as remarkable as it could be, making it one of the fastest spreading pandemics in recent times, atleast for India. ${ }^{2}$ The lightning spread of this virus has also prompted to seal borders, change immigration rules, business engagements, and erupted diplomatic hostility. Even before humanity could get a grasp to fight back the virus, it already caused over ten trillion in economic loss worldwide, shutting down businesses and plummeting stocks to their lowest. An estimated five to ten million jobs were vaporized overnight just in the States. ${ }^{3,4}$ India, with a service sector based economy, contributing a whopping $60 \%$ of total GDP, seems to take the biggest hit. ${ }^{5,6}$ About one hundred million jobs in India will be at risk post-COVID-19 lockdown stage with an estimated 15-30 percent layoff in several sectors. With economy nose driving and growth rates running into negatives, the Indian economy is going through its most challenging times. In this condition, even the most staunch employee unions are just but helpless. With reduced or no negotiating power of these unions, employees are most venerable than ever. Several companies have already offered their employees three options: Layoff with a pink slip, continue with a reduced salary, or taking indefinite leave with no pay until the economy revives. Needless to say, even the best of these three options will be the worst nightmare for any employee. To add to this woe is the uncertainty that is hovering over the world. No one knows for sure when we are going to get rid of this virus.

There are currently dozen-plus mathematical models predicting the disease trajectory for COVID 19..$^{7-11}$ The ICMR based Indian model, the Cambridge model, the Michigan Model, the Hopkins Model, The MIT Model, The Harvard Model.. and the recently published Singaporean model. Each of them sets a different time of closure with several disagreements between them (example: The ICMR model is an SEIR based approach that partitions the population into S (Susceptible), E(Exposed), I(Infectious), and $\mathrm{R}$ (Recovered) compartments taking in the additional 'exposed' (E) state between the $S$ and I states. The Michigan model doesn't consider these assumptions). Further, all these predictive models are subjected to numerous perturbations, each of which can drift towards a different trajectory and a different outcome. Most of these models further ignore asymptomatic infections - people with active viral infection without any clinical signs. In fact, there is hardly any way to know these elusive populations unless we do head by head testing - an arduous and nearly impossible task to accomplish for 1.2 billion people. Then there are regional variables, dietary habits, comorbidities, socio-economic conditions ... the list is endless that none of these models can ever account for. All we can have here is an educated guess. 
With an economy that was already in stagflation, ${ }^{12}$ there is little room for any negotiations. India's unemployment rate is currently at $5.36 \%$ as of Dec 2019 compared to $5.33 \%$ the previous year and with a labor force participation dropping to $49.29 \%$. The job loss rate across India was $17.51 \%$ in the week ended 7 June compared with $20.19 \%$ in the week ended 31 May. The rural unemployment rate improved marginally to $17.71 \%$ in the week ended 7 June from $17.92 \%$ in the week earlier, whereas rural job loss remains unaltered. Urban employment rose to $9.7 \%$ this January from $9 \%$ last year, indicating that a large chunk of people are still struggling to find a job even though the nation's GDP was rising. We have here an excellent example of jobless growth. Then there are numerous loopholes in the existing system. One of them is the absence of a National Employment Policy (NEP). With about 35\% of the country population in the age bracket 25-30 years, the youth workforce of India is expected to increase to approximately 600 million by the year 2022. What is sad is that just 3\% have any formal training. Further income inequality, gender bias, domestic violence accompanied by limited access to healthcare, primary education, and housing that were already prevalent in Indian society adds up to the woes. Post COVID19 world will be sprinkling salt on these exposed wounds.

\section{POST COVID-19 CRISIS}

\section{On economic health}

Post COVID19 will have a combined effect on this already complex demography of Indian job seekers. COVID 19 episode has reflected the lacunae of the system and how ill-prepared we are. Post lockdown has also witnessed one of the largest mass migration of the working and labor class due to abrupt closure of job site and construction places. Approx 40 million internal migrants were directly or indirectly impacted, creating a humanitarian crisis. With social distancing in effect and all means of transportation under seize, COVID19 has punched the hardest it can on this economically weaker sections. This has also exposed the deep-rooted problems and mismanagement that were never addressed. With no job security and no benefits, the shift of workforce from rural to urban India in search of a higher wage and the aspirations of climbing the social hierarchy might still be a daydream. A silver lining in this cloud is the beginning of a slow resume. As per the CMIE in its weekly report, workers (maids, cooks, drivers, cleaners, and construction workers) are now slowly back into the job. It is possible that in post COVID19 scenario, many of these migrant workers choose to remain in their parental village due to looming uncertainty in urban life, a decision that would have its consequences since this cheaper workforce is the engine for the real estate and infrastructure development and upscaling of urban cities. Though every other sector is sure to suffer from this current pandemic, the aviation sector is surely at the top of the list. It is going to embrace an estimated 2 trillion dollar worldwide loss with about 9000 crores in India alone. ${ }^{13}$ Then there are the connected businesses that thrive in the aviation industry. Sectors like the hotel, restaurant, travel agencies, and other hospitality-based services are destined to be doomed. It will take perhaps years or even decades to compensate for all these looses.

India's informal sector currently employs $80 \%$ workforce. ${ }^{14}$ That's a parallel economy in itself. Among the five South Asian countries, informalisation of labor is the highest in India and Nepal $(90.7 \%)$. The agricultural sector has the highest level of informal employment (93.6\%) around world. ${ }^{15}$ With prolonged lockdown and enforcement of social and physical distancing accompanied by a ban on transportation, India's agriculture sector is bleeding profusely. With laborers locked inside and unable to work in the field at the peak harvest season (Harvesting is in its peak in Haryana, Punjab, UP and is likely to be completed by the end of April 2020), the losses will undoubtedly be substantial. ${ }^{15,16}$ An extended lockdown will also hurt farmers to harvest the winter crop. Even though the union ministry of the government has exempted the agricultural sector from lockdown under the disaster management act, it is still far from providing any immunity. With transportation service under seize and cargo movement restricted across the country, goods were unable to be delivered at its destination. Though the government authorized the e-commerce industry to do the delivery, their hands are too full to carter to the needs. Even then, with shops and malls closed and lockdown enforced, the consumer demands were at the lowest. Perishable items like milk and poultry that heavily rely on cold chain logistics were at the receiving end. Post demonetization and implementation of Goods and Service Tax (GST) has already crippled India's vast informal sector. Added to this is an unwanted, uninvited, and un-anticipated COVID19 that completely took everyone by surprise. Quoting Jagannathan, Editor Swarajya, of the four engines of growth, two - private consumption and exports - are out of action, and the other two - public investment and private investment are under the weather. There seems hardly any safety net for the middle class and those below. It's like an aircraft in midair that has all its engines stalled.

As in their seminal article, RBI occasional papers, 2011, Janak Raj and Sangeeta Mishra righty said, for emerging economies like India, inflation is bound to happen due to supply chain shock. India's retail price inflation fell to a four-month low of 5.91 percent year-on-year in March 2020 from 6.58 percent in the previous month and slightly 
below market expectations of 5.93 percent. Post-COVID 19 will surely change these numbers. ${ }^{17} \mathrm{UN}$ has cautioned that the world is heading towards the brink of a "hunger pandemic". ${ }^{18}$ We are likely to face multiple famines of biblical proportions within months if nations don't act now, to avoid funding shortfalls and disruptions to trade due to COVID-19. Millions of civilians, including elders, women, and children, will be being pushed to the brink of starvation.

\section{Medical and mental health}

As per WHO, India ranks $184^{\text {th }}$ out of 191 in terms of the fraction of GDP spend on healthcare, making it one amongst the lowest when compared to other countries. With the Government spending on healthcare just at $1.15 \%$ of the GDP, there is very little room for maneuver. However, there is light at the end of the tunnel. With national schemes like AB-PMJAY (Ayushman Bharat-Pradhan Mantri Jan ArogyaYojana), a significant (approx ten crore) families were enrolled under this benefit program.

However, for a country of this dimension, more need to be done to address these pending issues that become more apparent during a pandemic. Assuming $80 \%$ availability of health care physicians, India has about ten lakhs, allopathic doctors registered under MCI and state bodies. Still, that account to about one doctor for every 1500 persons, ${ }^{19}$ much below the WHO recommended 1 per 1000. For COVID like highly contagious outbreak, where a significant number of healthcare personals are themselves infected, these numbers are highly insufficient and can quickly be overwhelmed by the surge in the number of new cases. And then we need to factor the fact that not all the physicians are trained to handle the infectious disease of this nature.

\section{Possible solutions}

There have been few suggestions as to how this pandemic will possibly end or how we as a nation might rebuild again. ${ }^{20,21}$ Social distancing and quarantine have surely an effect in containing the disease and flattening the transmissibility curve, but there is a limit as to how long peoples can be locked indoors. Clearly, this is a significant step to prevent community transmission but can't surely be the only one. Lockdown possibly has provided healthcare workers and first-line responders the breathing time to prepare for the worst, like setting up isolation wards, stockpiling medicines and essentials, and arranging for testing kits. Lockdown can be lifted in a staggered way zone by zone, district by district to monitor closely and pin down hotspots and cluster zones. The second scenario would be to bite the bullet and expose the public to the virus, prepared to embrace a mass emergency and imminent crisis with the hope that a substantial fraction will eventually develop "herd immunity" and break the transmission chain. For a country like India, $70 \%$ of individuals need to be exposed to obtain protective herd immunity, ${ }^{22}$ a too risky decision that policymakers will think twice to take. Even if $1 \%$ of this $70 \%$ need medical emergency and a fraction of them succumb for ventilator support, our existing healthcare system will be overwhelmed and invariably collapse. The $3^{\text {rd }}$ option will be a hide and seek like a game with the virus, where there will be episodes of lockdowns and some intermittent case by case relaxation until someone, somewhere come up with a usable drug or an effective vaccine to fight this virus. Else we may prepare to face the virus and accept all its rage and wait till it mutates out into a less lethal variety. But with the vaccine development pipeline painstakingly slow, we don't have a clear cut solution to this problem. ${ }^{23}$

There has been debate on how a pandemic of this magnitude can be managed and did we performed satisfactorily. It might still be premature to sign the report card, but needless to accept that most of the nations worldwide did terribly wrong in handing this outbreak. Not only the contingency plans insufficient and risk mitigation protocols haywire, but they are also too short-sighted, confused, and misplanned. We need to take the blame and accept that India should take all initiatives to becomes a center for excellence in research and development, not necessarily a hub for reverse engineering products and generic drugs. While we might take pride in our vast portfolios of NCE (Novel chemical entities), but these are again alternatives to preexisting compounds discovered elsewhere, and it's more important what we do with them than just having them. These might bring quick cash but not the backbone on which 1.3 billion populations can rely on. We need to set up a knowledge-based industryand take the lead in the development of novel antivirals, novel drug resistance antimicrobials, and novel oncology products. Though there is no definite treatment against COVID19 so far, Gilead bioscience product Remdesivar seems to be the most promising candidate. To build a novel science-based industry, we need a strong partnership between academia and corporates, fostering a close tie-up and collaborations and internship programs. ${ }^{24}$ What is good is off late we have started similar programs (BIRAC), something which should have been started long back.

\section{Concluding remarks}

COVID19 is a global pandemic that seems to overshadow everything. It successfully crossed international boundaries and stepped into 120 countries, infecting millions, and killing a significant number. More than human life, it created a massive global emergency tossing the economy of even the most stable countries. It has impacted the lives of every single person on this planet within a short span to seven months. It has been forced to shut down cities, 
states and countries, airports, and cargo. It has influenced the way we interact, we think, we behave, and we act. It has swept into our conscience and imaginations, and the way we used to do things may change forever. Humankind is going through a new and unprecedented experience altogether. The way we mingle with people is undoubtedly going to change. Every individual will be looked upon with suspicion and a potential disease carrier. Even worst will be someone exploiting social distancing as a means to marginalize and isolate peoples belonging to a particular clan, a section of the society, or belonging to specific religious faith. The community might be fragmented into tiers with even more demarcation than the existing one. International travelers might now be subjected to additional checks and restrictions to qualify for some sort of an immunity clearance that they are not disease carriers. With the economic downfall and loss of the business worldwide, unemployment will be sky rocketed. ${ }^{25}$ Further, with the shrinking market and surplus peoples around, men and women will be forced to work at an even lower salary and poor benefits. This will dramatically reduce the spending power and could choke the economy further that was already gasping for oxygen.With a mission to protect and revive the domestic economy, nations will be forced to reduce imports and immigration. Translate this to a country like India, where each state is different in so many ways from the rest. This will perhaps lead to unequal economic development spiking the purchasing power parity even further. The post-COVID world will probably be playing more defensive with an element of suspicion in the air. The fear of the virus is probably more than the virus itself. With crude oil hitting the lowest in half a century due to diminishing demand, oil-based economy clusters like the OPEC and the middle east will possibly start to venture additional source of income. The age-old reliable source of income seems to be too risky to rely on entirely. They have to expand their portfolios to different investments. Quoting a statement from a journal, "In today's interconnected world, economies and humans are linked far beyond their geographical borders"; hence an epidemic of this magnitude will send ripples across the globe. As Dr.Tedros Ghebreyesus, WHO Director has aptly said, "it is just not a public health crisis, it will touch every sector". With oil NSE down to -5.2 or by $5.26 \%$, an oil-dependent economy like Russia, UAE, and USA Shale gas will be hitting for bankruptcy with the crude oil price falling below 25 dollars. While temporality, that means some short term relief for oil-consuming countries like India, but very soon, we will be sucked into the tornadoes emerging out from bigger economies. An ailing economy will give the government less room to stretch out into programs like infrastructure building, healthcare, education, Science and Technology, Urban planning, etc. and lead towards a vicious cycle with three possible ways to revive again. A quick "V" type revival, which seems impossible in the present crisis, a delayed " $U$ " type revival which might take years to heal or a more probable "L" type revival where we might never achieve what we had before the pandemic and settle down to a new normal, a new set point and a new way to lead our life.

Along with the economy, we are expecting a tectonic shift in the social fabric of life. Sharing things, from sharing a cab, a sitting place, or an office space, will be strongly discouraged. With over $50 \%$ asymptomatic carriers, the stake is even higher. The comfort of a company will be replaced by solitude, an event that could snowball in an increase in the number of fragmented families. This will invariably come at the cost of mental agony and depression. COVID19 has indeed seen a surge in depression and mental breakdown. While the fear for contracting the virus will linger on, we are suddenly faced with new protocols of life like working from home, restricted assess to community pools, malls, theaters, playgrounds, stadiums along with a surge in unemployment and massive layoff, travel restrictions and difficulty in relying upon urban-based employments for the informal class. As recently published in NEJM, scars left from viral pandemic are not classified under posttraumatic stress disorder (PTSD), but nevertheless may lead to other psychopathologies, such as depressive and anxiety disorders.

The Post-COVID era is not all black and white. It's not all a tragic story either. For the first time in several decades, the pollution index in several cities seems to plummet. The sky is more transparent, and the pollution index of water bodies is perhaps at its lowest. The ozone hole appears to have healed considerably. Carbon footprints have reduced significantly. Sanitizers and hand soaps were valued more than coke and beer. Indeed we are going through a transition. Unfortunately, the payoff as collateral damages is just too disproportionate to endure. A collective effort fusing everyone's determination and energy will help us to overcome this nightmare and overcome the punch that a $30 \mathrm{~Kb}$ viral genome has rattled through the globe.

\section{REFERENCES}

1. http://www9.who.int/bulletin/volumes/89/7/11-088815/en/

2. https://www.livemint.com/news/india/covid-pandemic-growingfastest-in-india-11595854002224.html

3. https://www.deccanchronicle.com/business/in-other-news/ 100520/coronavirus-deals-us-job-losses-of-205-million-historicunemployment.html

4. https://economictimes.indiatimes.com/news/international/ business/americas-will-be-hardest-hit-by-covid-19-job-lossesinternational-labour-organization/articleshow/76038068.cms

5. https://www.lexology.com/library/detail.aspx?g=4d221d97-f7c4- 


\section{1d2-bf2f-fbe715cdf2bf}

6. https://theprint.in/economy/how-badly-has-coronavirus-hitindias-services-sector-q4-gdp-data-will-tell-us-today/431461/

7. https://thenextweb.com/neural/2020/04/29/ai-model-predictsthe-coronavirus-pandemic-will-end-in-december/

8. https://www.medrxiv.org/content/10.1101/2020.05.31.20118372v1

9. https://www.medrxiv.org/content/10.1101/2020.06.24.20139451v2

10. https://cloud.google.com/blog/products/ai-machine-learning/ google-cloud-is-releasing-the-covid-19-public-forecasts

11. https://healthitanalytics.com/news/stanford-launches-datadriven-model-evaluating-covid-19-interventions

12. https://theprint.in/talk-point/inflation-at-7-3-and-growth-at-5-isindian-economy-facing-stagflation/349378/

13. https://www.livemint.com/news/india/aviation-sector-faces-grimfuture-amid-covid-crisis-11592845087001.html

14. https://thewire.in/labour/nearly-81-of-the-employed-in-india-arein-the-informal-sector-ilo

15. https://economictimes.indiatimes.com/news/economy/ agriculture/govt-exempts-farm-activities-from-lockdown/ articleshow/74852730.cms?from=mdr

16. https://www.theguardian.com/commentisfree/2018/jan/13/india- 600-million-young-people-world-cities-internet

17. https://www.theguardian.com/commentisfree/2018/jan/13/india600-million-young-people-world-cities-internet

18. https://www.livemint.com/news/india/corona-has-pushedbharat-to-the-brink-11585845027852.html

19. https://www.business-standard.com/article/pti-stories/doctorpatient-ratio-in-india-less-than-who-prescribed-norm-of-1-1000govt-119111901421_1.html

20. https://www.niti.gov.in/niti/content/national-employment-policyindia-perspective

21. https://www.outlookindia.com/newsscroll/novel-drug-targetmay-lead-to-universal-antiviral-vaccine/1732423

22. https://www.thehindubusinessline.com/news/science/ covid-19-india-moving-towards-undeclared-herd-immunity/ article32259078.ece

23. https://science.thewire.in/health/coronavirus-vaccines-clinicaltrials/

24. https://www.birac.nic.in/description_new.php?id=286

25. https://www.clevelandfed.org/en/newsroom-and-events/ publications/economic-commentary/2020-economiccommentaries/ec-202009-unemployment-costs-of-covid.aspx

\footnotetext{
Author's contributions:

RD, BJ and SK-Compiled the manuscript; KP and AK-Assisted in writing; BJ and AK-Provided logistics and with helpful discussion; SK-Conceptulized the entire work.

Work attributed to:

Department of Biochemistry, AlIMS, New Delhi.

Orcid ID:

Dr. Ruby Dhar - (1) https://orcid.org/0000-0003-3600-6554

Dr. Arun Kumar - (1) http://orcid.org/0000-0002-8800-0296

Dr. Subhradip Karmakar - (1D https://orcid.org/0000-0002-4757-8729

Source of support: None, Conflict of Interest: None.
} 